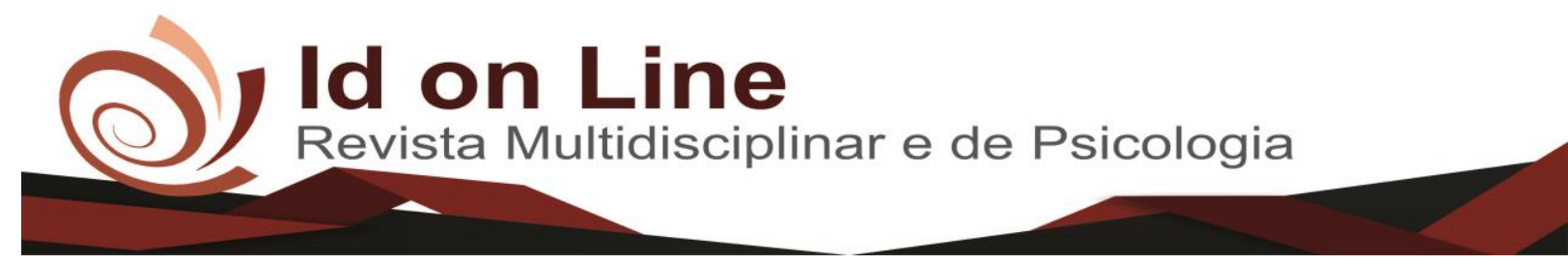

Artigo

\title{
Demonstração do Resultado do Exercício e suas Contribuições para o Ambiente Corporativo
}

\author{
Gabriela Lima Felix ${ }^{1}$; Tays Cardoso Dias ${ }^{2}$
}

\begin{abstract}
RESUMO
Com o intuito de visualizar de que modo a Demonstração do Resultado do Exercício pode contribuir para o ambiente corporativo, o presente trabalho evidência toda a estrutura deste relatório contábil buscando apresentar as informações mais relevantes contidas nele. A pesquisa destaca a definição e a importância de cada elemento da estrutura deste relatório. O objetivo foi o de apresentar as contribuições da DRE para as empresas por meio da sua estrutura e sua serventia como ferramenta de avaliação da saúde financeira da mesma, trazendo-se assim relevância para o gestor desempenhar seu papel gerencial de uma maneira eficaz e obtendo progressos no seu resultado. Utilizou-se de a pesquisa bibliográfica, classificando-se quanto aos objetivos sendo de natureza exploratória e uma abordagem qualitativa. Com esta pesquisa pode-se perceber que a elaboração desta demonstração é de suma relevância, pois por meio dela é perceptível o conhecimento financeiro-econômico da entidade com também é possível utiliza-la para a tomada de decisão assim melhorando cada vez mais a gestão na empresa.
\end{abstract}

PALAVAS CHAVE: Demonstração do Resultado do Exercício. Estrutura. Informações.

\section{Statement Of Income For The Year And Its Contributions To The Corporate Environment}

\begin{abstract}
In order to show how the Statement of Income can contribute to the corporate environment, this paper evidences the entire structure of this accounting report, aiming to present the most relevant information contained in it. The research highlights the definition and importance of each element of the structure of this report. The objective was to present the DRE's contributions to the companies through its structure and its usefulness as a tool to evaluate the financial health of the company, thus bringing about relevance for the manager to play his managerial role in an efficient way and making progress in its result. The bibliographical research was used, being classified in the objectives being of exploratory nature and a qualitative approach. With this research it can be seen that the elaboration of this demonstration is of great relevance, since through it the financial-economic knowledge of the entity is perceptible and it is also possible to use it for decision making, thus improving management in the company.
\end{abstract}

Keywords: Statement of Income for the Year. Structure. Information.

\footnotetext{
${ }^{1}$ Graduanda do Curso de Bacharel em Ciências Contábeis do Centro Universitário Doutor Leão Sampaio- UNILEÃO. gabyr7iurd@ hotmail.com

${ }^{2}$ Especialista em Contabilidade Tributária. Professora da UNILEÃO. taysdias@leaosampaio.edu.br
} 


\section{Introdução}

As demonstrações contábeis são informações e dados que uma empresa gera em determinado período. Dente as principais demonstrações temos a Demonstração do Resultado do Exercício, é um demonstrativo de imensa importância para os gestores, contendo informações relevantes notados na sua estrutura que são utilizados para a tomada de decisão. Para Padoveze (2017), é a segunda mais importante demonstração, ela evidencia lucros ou prejuízos acumulados durante determinado período.

Sabe-se que as demonstrações contábeis possuem papel significante em toda entidade. Portanto partindo desse pressuposto esse artigo busca responder: de que modo as informações da Demonstração do Resultado do Exercício (DRE) influenciam a tomada de decisão no ambiente corporativo?

Conhecendo a importância desses elementos, estabeleceu-se como objetivo apresentar as contribuições da DRE nas organizações para a tomada de decisão. Contendo também os objetivos específicos que são os de apresentar a estrutura, abordar informações contidas nela, e mostrar de que modo esta demonstração contribui na tomada de decisão.

Em resposta a tal questionamento surgiu à seguinte justificativa, no ambiente coorporativo os gestores estão em busca das informações que as demonstrações contábeisfinanceiras fornecem para avaliarem a saúde da empresa, pois elas possuem papel significante em toda entidade, dentre essas demonstrações tem-se a Demonstração do Resultado do Exercício (DRE). Esse trabalho propõe-se apresentar as informações contidas na Demonstração do Resultado do Exercício (DRE) e de como ela contribui nas organizações sendo ela uma das principais demonstrações possui grande serventia na apresentação da situação real da empresa no sentido financeiro, através dela podem verificar detalhadamente cada etapa desde a operação até a gestão. Compreende-se que os gestores podem avaliar qual regime tributário a empresa está adequada a participar, como vai o andamento da mensuração do lucro empresarial, e revela o desempenho gerencial e do progresso de resultados.

Para realização desta produção, utilizou-se dos métodos de tipologia bibliográfica, contendo objetivos de natureza exploratória, utilizando técnicas de documentação e abordagem qualitativa.

Portanto, considera-se que a pesquisa demonstra então que a DRE sendo um documento importante para a gestão de finanças do ambiente corporativo, contém informações financeiras que tem como finalidade diagnosticar a saúde da empresa, a partir das informações que são 
geradas os gestores podem contribuir com o planejamento estratégico da organização e assim os levarem à tomada de decisões futuras.

\section{Conceito e Objetivo da Demonstração do Resultado do Exercício}

A DRE é um demonstrativo contábil cuja finalidade é fornecer o resultado líquido de um exercício evidenciando o confronto das receitas, custos e despesas, é apurado através do princípio contábil do regime de competência onde "as receitas e as despesas devem ser incluídas na apuração do resultado do período em que ocorreram, sempre simultaneamente quando se correlacionam, independente de recebimento ou pagamento" (CFC, 1993 p.7).

De acordo com Iudícibus (2004), Demonstração do Resultado do Exercício é o relatório que traz o resumo parametrizado das receitas e despesas de uma empresa em determinado período, é apresentado de uma forma em que as receitas subtraem as despesas gerando um lucro ou prejuízo.

Para Marion (2009), a DRE é um demonstrativo contábil que gera informações relevantes através do confronto de despesas e receitas para a tomada de decisão, tendo como uma das principais funções confrontar todas as despesas realizadas, assim como as receitas que foram recebidas pela empresa no ano em questão. Sendo assim, se tornando uma forma de especificar todas as operações uma a uma, dentro dos grupos de contas patrimoniais a que pertencem.

A DRE tem como objetivo maior esclarecer como se formou a situação líquida da empresa no final do exercício, ao levar em consideração os valores recebidos, bem como os valores gastos com a atividade empresarial e deduzindo as despesas das receitas para que se obtenha o valor do lucro. Segundo Lins; Francisco Filho (2011), a DRE é o relatório contábil que evidencia o desempenho da empresa, ou seja, se ela teve lucro ou prejuízo dentre o período entre janeiro e dezembro de cada ano.

Segundo Marion (2003, p. 127) “A DRE é extremamente relevante para avaliar desempenho da empresa e a eficiência dos gestores em obter resultado positivo. O lucro é o objetivo principal das empresas".

Na opinião de Assaf Neto (2012), a DRE visa fornecer, de maneira esquematizada, os resultados (lucro ou prejuízo) alcançados pela empresa em determinado exercício social. Sendo assim objetivando o resultado econômico da empresa com a finalidade de trazer melhoria para a entidade, sempre em busca de lucro. 


\section{Obrigatoriedade da DRE}

Na visão de Marion (2009), o Demonstrativo de Resultados do Exercício, também conhecido pela sigla DRE, é uma demonstração contábil que cataloga todas as contas do balanço patrimonial da empresa para evidenciar e justificar o resultado líquido da mesma durante o exercício contábil.

A DRE é uma ferramenta financeira obrigatório, que deve ser publicada sistematicamente todos os anos fiscais. Por ser uma demonstração importante, deve ser elaborada por todas as empresas, seja ela de grande ou pequeno porte, pois irá evidencias o lucro ou prejuízo do período.

Segundo Padoveze (2017), esta demonstração para fins gerenciais será necessária sua elaboração para as empresas em geral ao final do exercício financeiro que equivale a um ano, e para as empresas de companhias abertas, com ações nas bolsas de valores, são obrigadas a apresentar a demonstração no período de três meses. Para fins societários e físcais, a obrigatoriedade é apresentar a demonstração do resultado anual.

A DRE deve ser elaborada de acordo com a lei vigente e porte da entidade. A obrigatoriedade do demonstrativo está prevista na lei $\mathrm{n}^{\circ} 11.638 / 2007$, com exigências específicas para sociedades anônimas (S.A.) e para sociedades limitadas (Ltda.). A obrigatoriedade também está definida pela lei no 6.404/1976 para sociedades anônimas.

Com sua exigência anual, alguns gestores optam por realizarem esse demonstrativo mensal ou trimestral, para facilitar o desenvolvimento da empresa.

\section{Estrutura da DRE}

A DRE é uma demonstração que visa o lucro e prejuízo acumulados, tem em sua estrutura contas que evidenciam as contas de resultado da entidade, dando ao administrador uma base de como está a situação financeira-econômica da empresa.

De acordo com Gonçalves (1996, p.315) “A Demonstração do Resultado do Exercício apresenta de forma resumida, as operações realizadas pela empresa, durante o exercício social, demonstrada de forma a destacar o resultado líquido do período".

A DRE é feita a partir das receitas obtidas no exercício fiscal, e tem validade de 12 meses. Braga (2012, p. 77) afirma: “ A demonstração do resultado do exercício deve apresentar o resumo das variações positivas (receitas ganhos) e negativas (custos, despesas e perdas) ". 
Segundo Iudícibus; Martins; Rubens (1995), Demonstração do Resultado do Exercício possui uma estrutura normatizada, contendo uma ordem cronológica para seguir, que foi estabelecida pela lei das S/A. Conforme a Lei das Sociedades por Ações, Lei $n^{\circ}$ 6.404, de 15 de dezembro de 1976, que dispõe em seu:

Art. 187: A demonstração do resultado do exercício discriminará:

I - a receita bruta das vendas e serviços, as deduções das vendas, os abatimentos e os impostos;

II - a receita líquida das vendas e serviços, o custo das mercadorias e serviços vendidos e o lucro bruto;

III - as despesas com as vendas, as despesas financeiras, deduzidas das receitas, as despesas gerais e administrativas, e outras despesas operacionais;

IV - o lucro ou prejuízo operacional, as receitas e despesas não operacionais e o saldo da conta de correção monetária (artigo $185, \S 3^{\circ}$ );

IV - o lucro ou prejuízo operacional, as receitas e despesas não operacionais; (Redação dada pela Lei $n^{\circ} 9.249$, de 1995)

IV - o lucro ou prejuízo operacional, as outras receitas e as outras despesas;

(Redação dada pela Medida Provisória no 449, de 2008)

IV - o lucro ou prejuízo operacional, as outras receitas e as outras despesas; (Redação dada pela Lei ${ }^{\circ} 11.941$, de 2009)

V - o resultado do exercício antes do Imposto sobre a Renda e a provisão para o imposto;

VI - as participações de debêntures, empregados, administradores e partes beneficiárias, mesmo na forma de instrumentos financeiros, e de instituições ou fundos de assistência ou previdência de empregados, que não se caracterizem como despesa; (Redação dada pela Lei no 11.941 , de 2009)

VII - o lucro ou prejuízo líquido do exercício e o seu montante por ação do capital social (BRASIL, 1976).

Através da estrutura da demonstração pode-se visualizar a situação real da empresa e com isso obter dados contábeis e gerenciais para tomada de decisão.

\section{Receita Bruta}

Esta conta está relacionada aos valores da venda de produtos e mercadorias ou da prestação de serviços durante um determinado período contábil, ou seja, o faturamento da organização.

É constituída pelo valor bruto faturado. O Faturamento representa o ingresso bruto de recursos externos provenientes das operações normais de venda a prazo ou a vista, no mercado nacional e exterior, de produtos, mercadorias ou serviços. Outras receitas de caráter operacional secundário devem figurar logo após o bruto, reservando-se para este, portanto, o papel de mostrar o resultado bruto da atividade operacional da empresa. (MATARAZO, 1995, p.69) 
No pensamento de Padozeve (2017), a receita bruta será o valor representado pela nota fiscal, sendo que excluído os impostos tais como ICMS, PIS, ISS e dentre outros.

Através do faturamento da organização pode-se obter a receita bruta, sendo ela o valor de venda dos produtos, valor de mercadorias ou o valor a prestação do serviço, ou seja, vendas brutas sem abatimentos.

\section{Deduções das Vendas}

São anulações realizadas pelos clientes causando um cancelamento de venda, uma dedução da receita bruta. Segundo Santos (2011), as devoluções de venda tratam-se do desfazimento de negócios que foram registrados como receitas brutas de vendas e serviços.

\section{Abatimentos}

Para Marion; Iudícibus (2002), são deduções dos preços de produtos, mercadorias ou da prestação de serviços concedidos com a intenção de gerar vantagens nas vendas e obter um bom lucro, geralmente são conhecidos como descontos incondicionais. "Os abatimentos e descontos sobre vendas e serviços são aqueles concedidos incondicionalmente, e normalmente são concedidos em função avarias ocorridas nas mercadorias" (SANTOS ET AL, 2011, p.27).

Estes abatimentos e descontos são concedidos para melhoria dos clientes sobre o preço do produto.

\section{Impostos Sobre Vendas}

Para Marion; Iudícibus (2002), compreende-se como encargos financeiros, na circulação de mercadorias tem-se o ICMS (imposto sobre operações relativas à circulação de mercadorias e sobre prestações de serviços de transporte interestadual, intermunicipal e de comunicação), na indústria o IPI (imposto sobre produtos industrializados), sobre a prestação de serviço o ISS (imposto sobre serviços de qualquer natureza), entre outros que são comuns em todas as áreas PIS (programas de integração social e de formação do patrimônio do servidor público) e COFINS (contribuição para financiamento da seguridade social). Para Santos (2011), os impostos que abrangem as vendas são os que possuem proporcionalidade com o preço das vendas ou dos serviços prestados. 


\section{Receita Líquida}

Com as deduções da receita bruta operacional, como as devoluções de vendas, abatimentos e impostos que incidem sobre a venda, obtém-se a receita líquida, ou seja, " receita líquida é a diferença entre receita bruta de vendas e as deduções de vendas". (SANTOS ET AL, 2011, p. 27).

Com o mesmo pensamento Braga (2012), descreve como receita líquida sendo a receita bruta menos as deduções das receitas.

\section{Custos}

Marion; Iudícibus (2002), descreve que relacionados a DRE, pode-se citar três custos, CMV (custo da mercadoria vendida), CPV (custo do produto vendido) e CSP (custo dos serviços prestado), ambos possuem a mesma finalidade que é a de simbolizar os gastos que se tem com a mercadoria e a prestação de serviços.

Com o mesmo raciocínio, Braga (2012) específica esses custos, CMV está relacionado aos custos relativos do estoque das mercadorias, CPV são os custos incorridos para a produção e CSP se encaixa nos incorridos na prestação de serviços.

\section{Lucro Bruto}

Braga (1999, p. 93), conceitua lucro bruto como, “a diferença entre a receita operacional líquida e os custos operacionais da receita."

Outra definição importante para lucro Bruto é dada por Silva (1999, p.154) "a diferença entre a receita de vendas e o custo da mercadoria vendida é denominada de lucro bruto. Essa diferença é importante, pois demonstra se a entidade está conseguindo vender seus produtos por um preço superior ao preço pelo qual foram adquiridos. "

Para Marion; Iudícibus (2002) o lucro bruto equivale a receita operacional líquida retirados os custos operacionais. O lucro bruto traz referência à diferença entre a receita líquida das vendas e serviços e o custo dos bens e serviços vendidos, ou seja, demonstra o quanto gasta para produzir o produto ou para realizar um serviço. 


\section{Despesas Operacionais}

Para Matarazzo (1995), são constituídas pelas despesas que são utilizadas para funcionamento das empresas, isto é, vender, administrar e financiar suas atividades e não se confundem com aquelas despesas utilizadas para transformar matéria prima em produto acabado.

Segundo Iudícibus; Marion (2002), despesas operacionais são esforços que a empresa faz durante um período para obter receita. Contendo o mesmo pensamento, Braga (2012, p. 79), define como "despesas que contribuíram para a realização das operações durante o período".

Para Iudícibus; Marion (2011, p. 57). “Os principais grupos de despesas operacionais são despesas de vendas, despesas administrativas e despesas financeiras”. As despesas operacionais, são gastos necessários para a venda de produtos, administrar a empresa e financiar as operações que requerem o uso de receita.

\section{- Despesas de Vendas}

São gastos relacionados diretamente relacionado com as vendas, como propaganda e publicidade, salários de vendedores entre outros.

Para Iudícibus; Marion (2011), são aquelas que estão desde a promoção do produto até sua colocação para a venda, ou seja, desde a sua comercialização até a sua distribuição. Vai abranger o pessoal relacionado a venda, propaganda e publicidade.

\section{- Despesas Administrativas}

Utilizadas para a administração da empresa, gastos do escritório e de outros setores que visam a gestão da empresa. Para Iudícibus e Marion (2011), são honorários administrativos, salários e encargos sociais, seguro de escritório, depreciação de móveis e utensílios, matérias de escritórios entre outros.

\section{- Despesas Financeiras}

São pagamentos aos capitais de terceiros, como: juros pagos ou incorridos, descontos concedidos, comissões bancárias entre outros. As despesas financeiras devem ser balanceadas com as receitas financeiras que são aquelas que podem ser deduzidas de despesas.

Segundo Braga (2012 p.80): 
Compreende-se as despesas com as áreas administrativas da empresa- salários de empregados dos órgãos de pessoal, contabilidade e finanças e respectivos encargos, honorários dos administradores, depreciação de bens utilizados nas áreas administrativas etc.

As despesas financeiras irão compreender todos os equivalentes administrativos que uma empresa possui.

\section{- Receitas Financeiras}

Para Santos et al (2011), receitas financeiras são rendimentos recebidos de aplicações financeiras e atualizações monetárias dos direitos da entidade, ou seja, são os rendimentos que trazem benefícios para a empresa.

"Considera-se Receitas Financeiras os ganhos operacionais derivados de operações financeiras, são exemplos: juros e descontos ativos, variações monetárias ativas e entre outros". (COUTINHO ET AL, 2010).

De modo geral as receitas financeiras são rendimentos de aplicações financeiras e atualizações monetárias cuja atitude faz com que a empresa seja beneficiada.

\section{Outras Receitas e Outras Despesas operacionais}

Não enquadradas no grupo de vendas, administrativas e financeiras. Outras despesas temos despesas tributárias, prejuízos oriundos das aplicações em outras empresas, já nas outras receitas tem-se lucros de participações em outras sociedades.

Contendo os mesmos pensamentos, Santos et al (2011), retrata que são relacionados a esse tópico os resultados provenientes de atividades acessórias da empresa, tendo um exemplo de participações em outras sociedades, os dividendos recebidos.

\section{Resultado Antes do Imposto de Renda e da Contribuição Social Lucro Líquido}

Braga (2012) ressalta que é o valor correspondente da diferença entre receitas, custos e despesas citados anteriormente. Caso o valor seja positivo teremos um lucro, que obtido antes de qualquer participação será utilizado na compensação do prejuízo. E se houver um prejuízo será deduzido do lucro para determinar a base de cálculo da provisão do Imposto de Renda. 


\section{Resultado depois do Imposto de Renda e da Contribuição Social Lucro Líquido}

De acordo com Braga (2012) é o resultado obtido após a dedução da provisão do IR e da CSLL, caso haja prejuízo acumulado, ou seja, não restando lucro para constituição de provisão para o IR, não será constituída, sendo assim será o resultado operacional do período que transita para a conta lucros acumulados para fins de compensação, que poderá ser parcial ou total.

\section{Participações e Contribuiç̃̃es}

De acordo com o artigo 189 da lei das S/A (6.404/76), do resultado do exercício, serão deduzidos, antes de qualquer participação, os prejuízos acumulados e a provisão para o imposto sobre a renda, este mesmo artigo prevê as participações que serão beneficiadas pelas atividades da empresa, tais como: debêntures, administradores, partes beneficiárias e empregados para instituições ou fundos de assistência ou previdência de empregados.

De acordo com a mesma lei em seu art. 190:

As participações estatutárias de empregados, administradores e partes beneficiárias serão determinadas, sucessivamente e nessa ordem, com base nos lucros que remanescerem depois de deduzida a participação anteriormente calculada. (BRASIL, 1976).

Caso estejam determinadas no estatuto da empresa, deverão ser pagas estas participações e contribuições aos devidos beneficiários.

\section{- Debêntures}

Iudícibus e Marion (2011), ressaltam que debênture são empréstimos que podem ser solicitados pela companhia à público em geral, pagando juros e concedendo amortização em geral, com isso, emitirão títulos a longo prazo com garantias, chamando-os de debêntures.

De acordo com a lei 6.404/76 no art. 52. "A companhia poderá emitir debêntures que conferirão aos seus titulares direito de crédito contra ela, nas condições constantes da escritura de emissão e, se houver, do certificado".

As debêntures são empréstimos em forma de títulos a longo prazo que as companhias podem emitir a pessoas que possuem o direito a ela. 


\section{- Administradores e Empregados}

Para Iudícibus; Marion (2011), esse complemento sobre a participação do lucro é definido por um estatuto ou contrato social, e com a constituição de 1988, passou a ser obrigatório.

\section{- Partes Beneficiárias}

São concedidas para as pessoas tais como fundadores que são os titulares desses títulos que têm direito a participação nos lucros anuais.

As contribuições para Partes Beneficiárias de acordo com a lei (lei 6.404/76, art. 46), "são títulos negociáveis sem valor nominal,sem o capital social e que concede ao seu titular direito eventual de crédito contra a companhia consistente na participação nos lucros da sociedade ", neste mesmo artigo esses títulos são tratados como direito de crédito é eventual, uma vez que não poderá ser exigido se a companhia não registrar lucro para distribuir.

Segundo a lei das Sociedades por Ações (6.404/76), no art. 47. "As partes beneficiárias poderão ser alienadas pela companhia, nas condições determinadas pelo estatuto ou pela assembleia-geral, ou atribuídas a fundadores, acionistas ou terceiros, como remuneração de serviços prestados à companhia."

Sendo assim, as partes beneficiárias que são os acionistas, fundadores ou titulares, recebem direto de crédito para participarem dos lucros líquidos anuais que a empresa obteve.

\section{Contribuições ou Fundos de Previdência}

Iudícibus; Marion (2011), ressaltam que são doações com o intuito de assistir ao quadro de funcionários às previdências particulares para complementar a aposentadoria, são definidos pelo estatuto e serão deduzidas com uma participação nos lucros anuais.

\section{Lucro ou Prejuízo Líquido do Exercício}

Após a compensação de cada uma das responsabilidades que as empresas possuem durante todo um período, pode-se obter o resultado líquido do exercício. Para Braga (2012), o 
lucro se refere a operação final do exercício, se houver um resultado positivo será lucro e se houver um resultado negativo será prejuízo.

Seguindo o mesmo pensamento os autores Iudicíbus e Marion (2004), citam que o lucro é a diferença entre o Lucro Bruto e as despesas operacionais.

O lucro Líquido pela definição de Marion (2003) é o que restou de líquido à disposição dos sócios ou acionistas, depois realizada as necessárias deduções.

Para ter uma melhor visão sobre a estrutura da demonstração tem-se um exemplo:

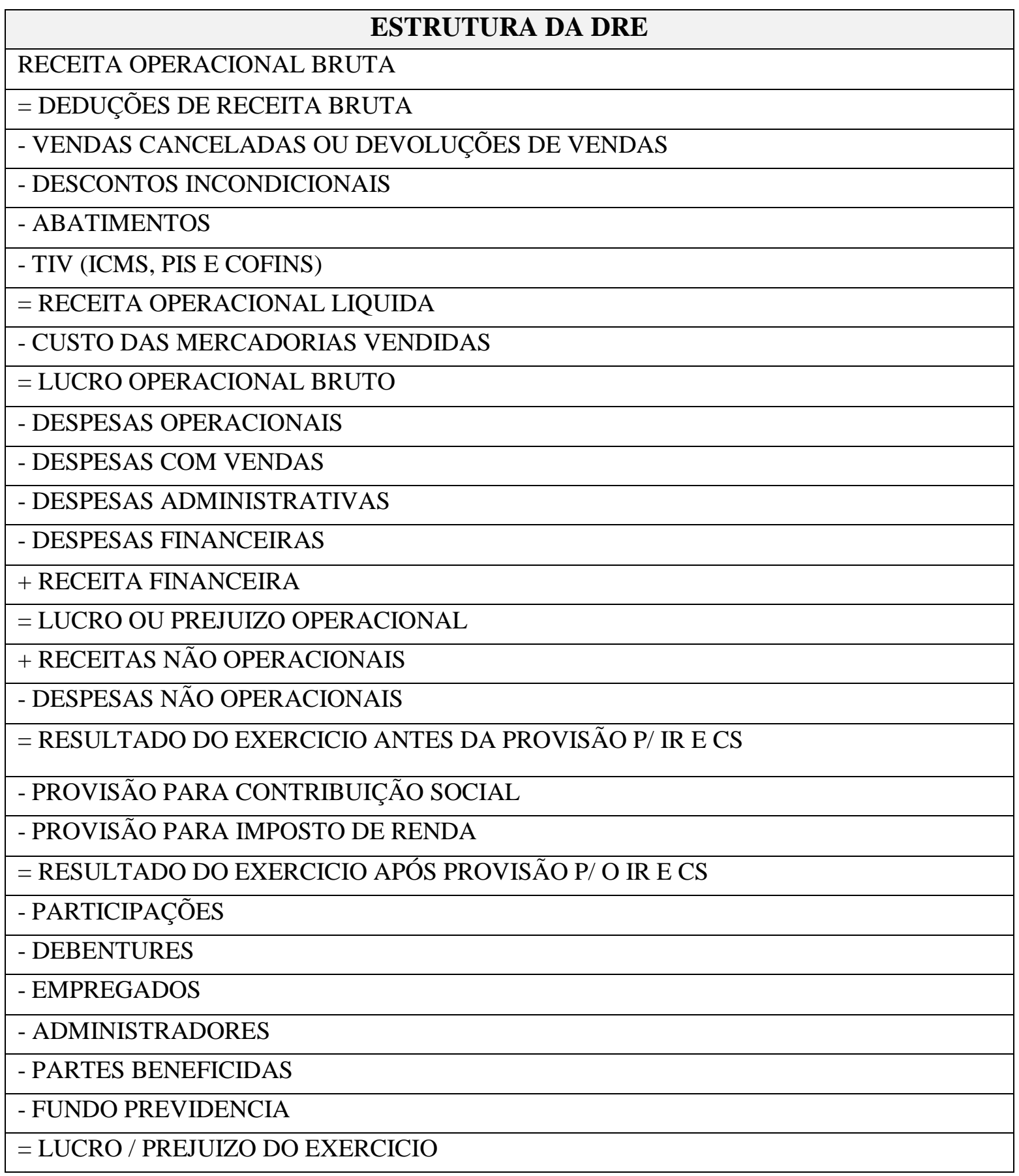

Fonte, SARDAGNA, 2018 (adaptado) 


\section{Contribuições para o Ambiente Corporativo}

A DRE sendo um demonstrativo contábil - financeiro tem o objetivo de auxiliar os gestores no ambiente corporativo, tornando-se possível obter um melhor desempenho, sem as informações fornecidas pela $\underline{\mathrm{DRE}}$ os gestores não serão capazes de avaliar a verdadeira realidade da empresa.

Para Ribeiro e Marion (2017), ela irá fornecer dados básicos e essenciais a formação de uma análise da formação do resultado do exercício. As informações levantadas por meio da análise são úteis a diversos usuários, como futuros investidores, sócios, credores, instituições financeiras, clientes, governo, gestores, entre outros.

Pelo resultado obtido na conta de Receita Líquida que será a receita bruta diminuída as deduções estabelecidas pela lei 6.404/76, que são os impostos, deduções e abatimentos, que segundo Marion (2009), são aqueles que incidem diretamente sobre as operações de vendas de acordo com as atividades operacionais, através desta dedução é possível visualizar se a empresa obteve bom ou péssimo desempenho na receita, é de suma importância o conhecimento destes impostos e seus valores pois é através do conhecimento que lhe é oferecido redução nos custos da empresa, transparência aos consumidores e favorece a regularização fiscal, contribuindo assim para serem geradas informações relevantes, resultando uma tomada de decisões que ocasionará proatividade para a empresa.

Através do resultado do Lucro Bruto, que é a receita líquida confrontada com o custo da mercadoria vendida que de acordo com Marion (2009), é uma dedução e na apuração do resultado será deduzido da receita líquida de vendas, assim, permitindo os gestores avaliarem o equivalente de lucro que a empresa obteve durante seu período, e traçarem metas para alcançar um lucro mais favorável, concluindo-se que, todo e qualquer administrador de empresas buscam lucratividade para o seu negócio.

Na apuração da conta Lucros ou Prejuízos operacionais, trata-se do rendimento que obtém-se antes das deduções de imposto de renda e contribuições sobre o lucro líquido que quando analisados traz uma realidade onde a gestão pode-se ter um valor que foi calculado após as deduções de despesas e receitas do período.

Após apuração da conta de Lucros Antes Do IR e CS, que traz a dedução das provisões de imposto de renda e de contribuições, temos ao Resultado do Exercício Após a Provisão de IR e CS, é deduzido todas as participações, que como já relatado são as de debêntures, empregados, administradores, partes beneficiárias e fundos de previdência, que resultará no Lucro ou Prejuízo do Período, onde através dele os usuários das informações procuram 
analisar através dos indicadores, obtendo assim um resultado para tomada de decisão favorável para a empresa. Tornando a DRE um elemento de simulação de panoramas que facilitam a ação do gestor no futuro.

A DRE sendo uma ferramenta para a gestão empresarial, auxilia na geração de informações que irão permitir que os dados apresentados sejam confiáveis para utilização no planejamento financeiro.

\section{Metodologia}

A metodologia aderida em uma pesquisa científica destaca como os trabalhos são realizados, qual foi a abordagem, métodos e técnicas utilizadas ao decorrer da pesquisa, obtendo assim respostas a problemática levantada. Para Silva (2003, p. 25) "a metodologia é o estudo no método na busca de determinado conhecimento". Na metodologia irão ser aplicados diversas técnicas, métodos e materiais.

Há diversos tipos de procedimentos de pesquisas, são citados por Severino (2014), a bibliográfica, documental, experimental e de campo. Conforme Andrade (2005, p.14) referente às tipologias de pesquisa bibliográfica, afirma que: "na pesquisa bibliográfica os fatos são observados, registrados, analisados classificados e interpretados sem que o pesquisador interfira nos fatos. " Com o mesmo pensamento Gil (2002), retrata que pesquisa bibliográfica é a pesquisa elaborada com base em materiais já desenvolvidos, como principalmente de artigos científicos e livros. Neste contexto, a metodologia empregada se classifica como sendo pesquisa bibliográfica, que constou com a opinião de autores como Marion e Braga sobre o assunto pesquisado.

Já no que diz respeito à forma de abordagem, a pesquisa se classifica como qualitativa e quantitativa, a primeira irá identificar os conceitos e as variáveis relevantes de objetos que podem ser estudados quantitativamente. Já a segunda utiliza-se de dados estatísticos para a análise. No presente artigo utilizou-se de uma abordagem qualitativa.

Godoy (1995, p. 58) reflete que:

\footnotetext{
“A pesquisa qualitativa não procura enumerar e/ou medir os eventos estudados, nem emprega instrumental estatístico na análise dos dados. Parte de questões ou focos de interesses amplos, que vão se definindo a medida que o estudo se desenvolve. Envolve a obtenção de dados descritivos sobre pessoas, lugares e processos interativos pelo contato direto do pesquisador com a situação estudada, procurando compreender os fenômenos segundo a perspectiva dos sujeitos, ou seja, dos participantes da situação em estudo."
} 
Também de acordo com Severino (2014), quanto aos objetivos, a pesquisa se classifica como sendo de natureza exploratória, sendo aquela que visa levantar informações sobre algo em questão, determinando assim um campo de trabalho.

\section{Considerações Finais}

Esta pesquisa tratou de uma busca por resposta sobre de que modo a Demonstração do Resultado do Exercício, conhecida também como DRE, influência nas decisões no ambiente corporativo. Destacou-se a estrutura detalhada deste demonstrativo contábil-financeiro, abordando as informações que o contém.

A DRE por ser um relatório de extrema importância e de responsabilidade financeira, sua regularização está contida na lei 6.404/76, que define como deve ser elaborada, quando elaborada de acordo com essas leis e modelo apresentado neste trabalho, ela pode gerar informações relevantes para a tomada de decisão dos gestores possibilitando maior segurança.

Quanto a obrigação desta demonstração considera-se que é relevante todas as empresas elaborarem, mas dependendo do porte da empresa é obrigatório a sua publicação. É através da elaboração da DRE, que os gestores analisam a situação da empresa evidenciando assim se ela teve lucro ou prejuízo, e já visando de que forma poderá obter melhoria no futuro.

Quanto a estrutura do relatório contábil, ela irá apresentar como já foi citado a situação real financeira - econômica da organização, trazendo facilidade para a gestão atuar de uma maneira precisa para torna-se possível obter melhor desempenho.

Considera-se então que a Demonstração do Resultado do Exercício é um documento importante para a gestão de finanças de uma organização, pois traz informações financeiras a partir de suas receitas e despesas realizadas durante o período contábil. Podendo ser elaborada mensalmente, trimestralmente ou anualmente, tem como finalidade diagnosticar a saúde da empresa, e a partir desta informação gerada por esse documento o gestor se organiza para contribuir com o planejamento estratégico da organização e no embasamento à tomada de decisões futuras.

Sugere-se para pesquisas futuras que seja realizado um estudo de caso para ressaltar quais as demais contribuições que essa demonstração proporciona para as entidades. 


\section{Referências}

ASSAF NETO, Alexandre. Estrutura e análise de balanços: um enfoque econômico financeiro. 10. ed. São Paulo: Atlas, 2012.

, Estrutura e Análise de Balanço: São Paulo. Ed. Atlas; 1998.

AZEVEDO, Marcelo Cardoso de. Estrutura e análise das demonstrações financeiras. 2.ed. - Campinas, SP: Alínea, 2013.

BRAGA, Hugo Rocha. Demonstrações Contábeis: Estrutura, Análise e Interpretação. 7.ed São Paulo, SP: Editora Atlas S.A., 2012.

BRASIL. LEI 6.404/76 - Lei das Sociedades Por Ações. Disponível em: <http://www.planalto.gov.br/ccivil_03/LEIS/L6404consol.htm >. Acesso em 5 ago. 2018.

BRASIL. LEI 11.638/2007. Disponível em: <https://www.planalto.gov.br/ccivil_03/_ato20072010/2007/lei/l11638.htm> . Acesso em 5 ago.2018.

COUTINHO, Átino de Souza; et al. Contabilidade Financeira. 2.ed. Rio de Janeiro: Editora FGV,2010.

GIL, Antonio Carlos. Como elaborar projetos de pesquisa. 4. ed. São Paulo: Atlas, 2002.

GODOY, A. S. (1995). Introdução à pesquisa qualitativa e suas possibilidades. Revista de administração de empresas. p. 58. Disponível em: < https://rae.fgv.br/>. Acesso em 28 out. 2018.

GONÇALVES, Eugênio Celso; BAPTISTA, Antônio Eustáquio: Escrituração. In_Contabilidade Geral. 3. Ed. São Paulo: Atlas, 1996.

IUDÍCIBUS, Sérgio de. Teoria da Contabilidade. 7. ed. São Paulo: Atlas, 2004.

IUDÍCIBUS, Sérgio de; MARION, José Carlos. Introdução à Teoria Da Contabilidade Para O Nível De Graduação. 3. ed. São Paulo: Atlas, 2002.

Curso De Contabilidade Para Não Contadores. 7.ed. São Paulo: Atlas, 2011.

Contabilidade Comercial. 6. ed. São Paulo, Atlas, 2004.

IUDÍCIBUS, Sérgio de; MARTINS, Eliseu; RUBENS, Ernesto. Manual de Contabilidade das Sociedades por Ações. 4. ed. São Paulo: Atlas, 1995.

IUDÍCIBUS, Sérgio de; et al. Contabilidade Introdutória. 11. ed. São Paulo: Atlas, 2010.

LINS, Luiz dos Santos; FRANCISCO FILHO, José. Fundamentos e Análise das Demonstrações Contábeis: Uma Abordagem Interativa. 1. ed. São Paulo: Atlas, 2011. 
MARION, José Carlos. Análise Das Demonstrações Contábeis: Contabilidade Empresarial. 5. ed. São Paulo: Atlas, 2009.

Contabilidade Empresarial. 10a ed. São Paulo: Atlas, 2003.

MATARAZZO, Dante Carmine. Análise Financeiras De Balanços. 3.ed. São Paulo: Atlas, 1 995.

PADOVEZE, Clovés Luís. Contabilidade Geral - Facilitada. 1. ed. Editora: GEN - Método, 2017.

RESOLUÇÃO. NBC TG 26 - Apresentação das Demonstrações Contábeis. Disponível em: $<$ https://www.diariodasleis.com.br/legislacao/federal/219169-nbc-tg-26-apresentauuo-dasdemonstraues-contubeis-altera-a-nbc-tg-26-apresentauuo-das-demonstraues-contubeis.html >. Acesso em 09 ago. 2018.

RESOLUÇÃO. CFC No 750/93 - Princípios Fundamentais de Contabilidade (PFC). Disponível em: http://portalcfc.org.br/wordpress/wp-content/uploads/2013/01/Livro_ Principios-e-NBCs . Acesso em 09 ago. 2018.

RIBEIRO, Osni Moura; MARION, José Carlos. Introdução à Contabilidade Gerencial. 3. ed. São Paulo: Saraiva, 2017.

SANTOS, José Luiz dos. Introdução à contabilidade. 2. ed. São Paulo: Atlas, 2011.

SANTOS et al. Introdução à Contabilidade: Atualizada pela Lei ${ }^{\circ}$ 11.941/09 e pelas Normas do CPC. 1. ed. São Paulo: Atlas, 2011.

SARDAGNA, José Carlos. Modelo de DRE - Demonstração do Resultado do Exercício. 12 mar. 2018. Disponível em: < https://blog.contaazul.com/modelo-de-dre/ . Acesso em 10 ago. 2018.

SILVA, Antonio Carlos Ribeiro de. Metodologia da pesquisa aplicada à contabilidade: orientações de estudos, projetos, relatórios, monografias, dissertações, teses. São Paulo: Atlas, 2003.

SILVA, José Pereira da. Análise Financeira Das Empresas. 4.ed. São Paulo: Atlas, 1999.

Como citar este artigo (Formato ABNT):

LIMA, Igor Moreira; FOGAÇA, Larissa Costa Silva. Ocorrência de Staphylococcus aureus em Queijos Minas Padrão Comercializados no Munícipio de Vitória da Conquista - Bahia. Id on Line Rev.Mult. Psic., 2019, vol.13, n.43, p. 828-844. ISSN: 1981-1179. 